\title{
Inmovilismo inmobiliario: ¿Arquitectura sin arquitectos?
}

La explosión demográfica y económica que ha experimentado Santiago en los últimos veinte años ha supuesto un incremento de las intervenciones inmobiliarias, destinadas éstas a suplir las necesidades habitacionales más inmediatas de los santiaguinos y a constituirse, principalmente, en un buen negocio, a pesar de los avatares propios de toda operación financiera a mediana y gran escala.

Como toda propuesta arquitectónica, el negocio inmobiliario -y uso la palabra negocio para ilustrar de la mejor forma posible este fenómeno- no ha estado exento de falencias a la hora de evaluar este proceso desde la óptica de la arquitectura. Más allá de consideraciones románticas o dogmatismos, debemos coincidir en que los resultados, en su gran mayoría, no satisfacen plenamente el buen paladar arquitectónico. A vuelo de pájaro, se puede percibir un cierto conformismo en la acción inmobiliaria y una adecuación de la arquitectura a los mínimos necesarios requeridos para agradar a la masa ciudadana, convertida en este caso en cliente.

Por lo mismo, las soluciones tipo y la autocomplacencia abundan en este escenario urbano, mezcla peligrosa de rutina y reduccionismo arquitectónico. La premisa se sustenta en el éxito del producto y desecha la calidad del objeto en función de la satisfacción comercial. La chapa de ladrillo y la martelina color beige se han apoderado de casi todas las comunas del Gran Santiago y han hecho del habitar, otrora campo experimental de la arquitectura, un hecho común reducido a estadística o modelo probado y probable. De esta forma, las soluciones que exploran en las aristas de la búsqueda arquitectónica o que se permiten superar los estándares dictados por el siempre omnipotente Mercado, son saludadas con vítores y loas por un gremio que se ha acostumbrado a la ausencia de innovación en este campo y ha perdido la capacidad de asombro ante tanto lugar común.

Los arquitectos nos hemos entregado, casi sin reclamo ni remordimientos, a los vaivenes de un mundo inmobiliario, tan dinámico como conformista. Eso sí, siempre que los números se tiñan de azul y la ecuación arroje resultados positivos. Pareciera ser que la gran mayoría de los arquitectos nos hemos acostumbrado a la manida tipología sin análisis crítico ni propuestas relevantes que reviertan la tendencia y eviten el tedio que la repetición de tanta solución nos propone.

Ante esta forma de operar, resulta inevitable hoy recordar las caricaturas que películas como Metrópolis planteaban en los años 20 respecto de ciudadanos comunes entregados como máquinas a la rutina de la repetición de acciones que no pasaban necesariamente por el filtro siempre indispensable de la razón. Cabe hacer notar que aquí no hemos tocado hasta el momento ningún punto referente a lo apropiado o no de la mutación que la ciudad experimenta a partir del reemplazo de una unidad unifamiliar por otra multifamiliar, o los efectos que suponen el aumento de la altura, la población y el cambio de escala sobre el entorno inmediato que rodea a toda operación inmobiliaria. Ni hablar de consideraciones respecto al impacto que esto puede tener sobre la vida de dicho lugar, antes y después de la intervención.

En realidad, he querido centrarme principalmente en el hecho de la poca o nula búsqueda que muchas operaciones inmobiliarias plantean al momento de proponer la solución final, definida más a la luz del negocio fácil que de la arquitectura. Es por esta razón que este artículo se hará cargo del breve análisis de un edificio que parte de la premisa que, al menos y a mi modesto parecer, pretende superar la solución fácil y explorar en los confines de la arquitectura una solución que satisfaga tanto las necesidades financieras del mandante como las aspiraciones habitacionales del usuario. Lo más interesante de todo esto es que se parte de una problemática urbana, teniendo a la arquitectura como eje ordenador y finalidad del proceso.

La obra en comento es el Edificio Atenea, diseñado por los arquitectos Beatriz Stäger y Rodrigo Chauriye -éste último es además académico de nuestra facultad-, el cual se encuentra ubicado en la comuna de Las Condes y que fue edificado entre los años 2006 y 2007. Lo interesante de este edificio, más allá de sus cualidades plásticas, es la base de su diseño, el cual nace tanto del análisis del lugar físico en el cual se inserta como de la intención de responder a una tipología habitacional que contrarreste el modelo de densificación a gran escala, que prima especialmente en el centro de Santiago y en algunos lugares de la misma comuna de Las Condes. Aquí radica su mayor valor arquitectónico, en la capacidad de trabajar a pequeña escala y con gran detalle soluciones que se han convertido en modelos repetitivos y que hacen del volumen un valor.

Hace algunos años, tanto en el mundo del turismo como en el gastronómico, nació un concepto que resume este tipo de condiciones y que apela a la pequeña escala y al detalle fino. Dicho concepto, muy manido respecto a la moda, es el de boutique, lo cual supone un confort superior a partir del trato personalizado. Sin querer caer en exageraciones ni entusiasmos desmedidos, podríamos plantear a través de esta obra la idea de un edificio boutique, preocupado de los pequeños detalles, los cuales en su conjunto van dando forma al objeto global.

Desde ese particular punto de vista, y a modo de ejemplo, el trabajo que los arquitectos hacen en la zona de ingreso y recepción respecto a la unificación del espacio a través del uso de un solo material como revestimiento en todas sus superficies, o la elección de un cromatismo común para la chapa de madera en los departamentos habla de una

\footnotetext{
Arquitecto Universidad de Chile. Máster en Historia, Arte, Arquitectura y Ciudad Universitat Politècnica de Catalunya. Magíster en Artes, Mención Teoría e Historia de Arte, Universidad de Chile.
} 


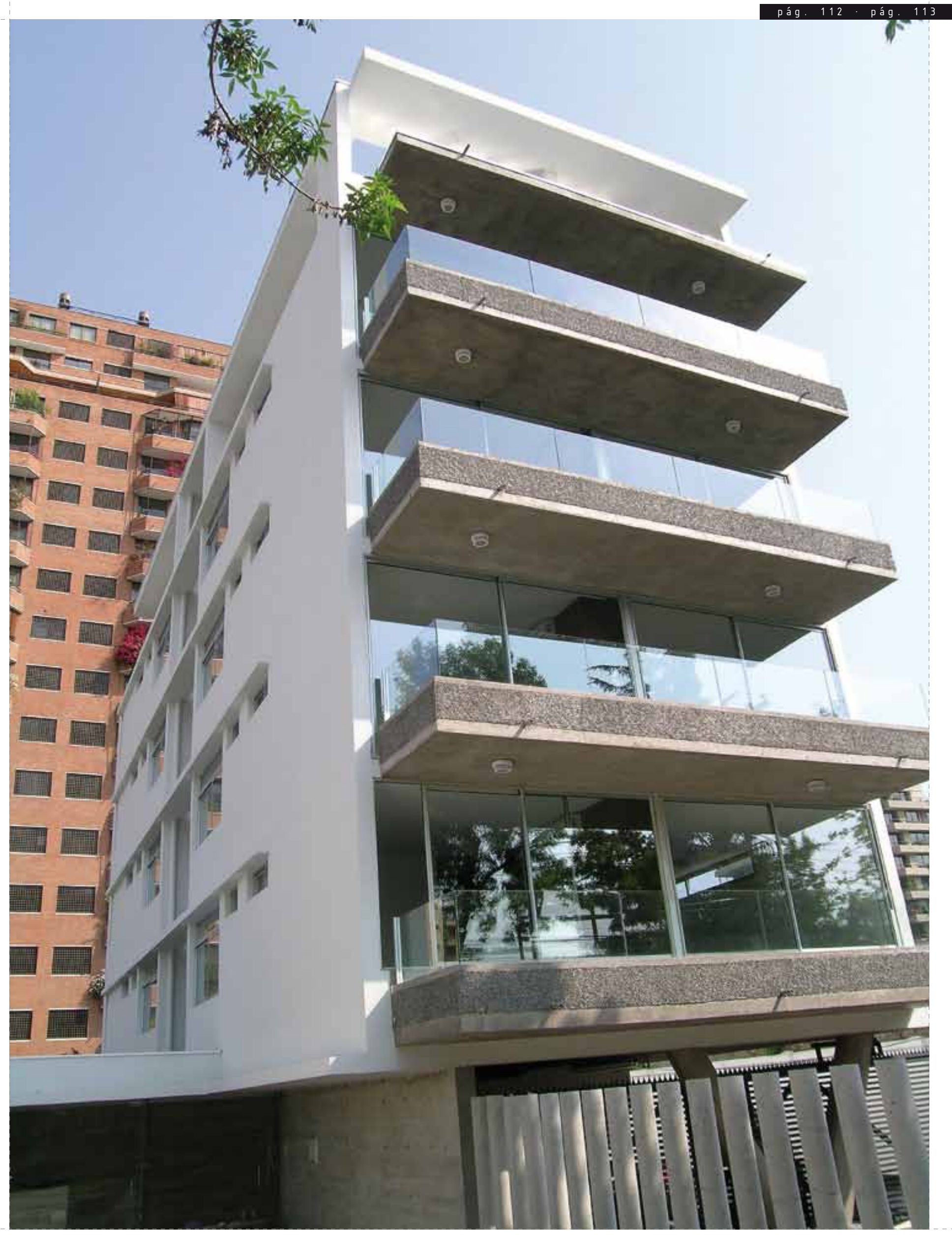




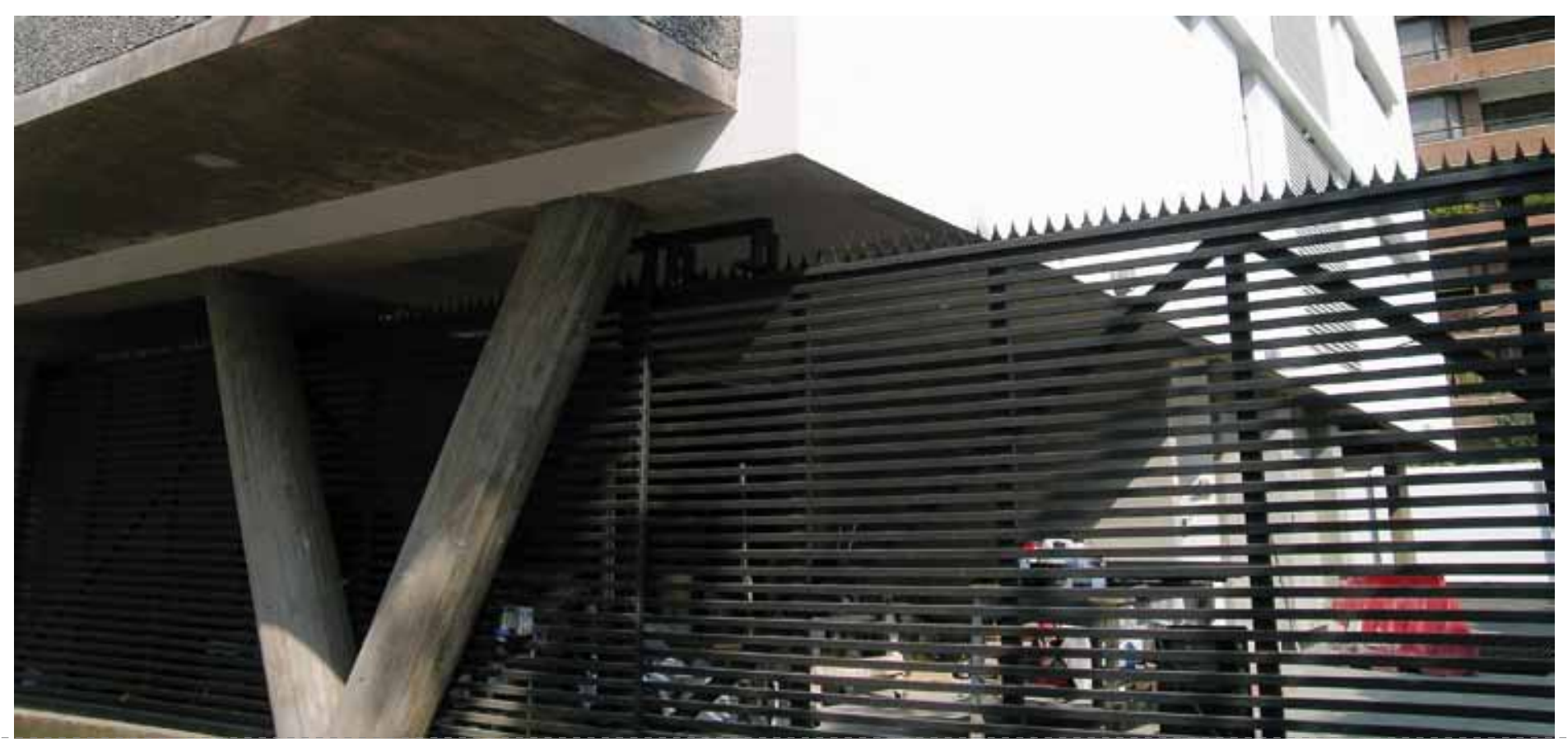

preocupación por la apariencia estética de la espacialidad del edificio, que redunda directamente en la calidad de éste. Esta misma preocupación se repite tanto en los balcones como en la geometría de las fenestraciones, lo que le otorga al conjunto un valor agregado que excede la impronta inmobiliaria.

Claramente la obra supera los mínimos necesarios que el negocio importa.

Amén de lo anterior, es posiblemente en el tratamiento de la espacialidad interior de los departamentos y, especialmente, en la solución dada a ellos lo que le otorga el mayor valor al edificio. En este sentido Chauriye y Stäger han optado por un espacio flexible, el cual intenta obviar las divisiones en la medida de lo posible. Para estos efectos, los arquitectos optan por separar la parte pública de la privada exclusivamente a través del mobiliario, en este caso, los closets de cada habitación. Respecto de la cocina, se plantea un sistema semiabierto, conectándose con la zona de living comedor sólo a través de una pequeña interrupción del muro y la aparición de un mueble de apoyo. Este sistema de conexión/ división supone una mayor flexibilidad para el espacio y el aprovechamiento del mobiliario en funciones anexas, que no necesariamente le son propias, confiriéndole mayores posibilidades al espacio total. Este solo hecho plantea la adopción de una tipología distinta a la tradicional para departamentos de dos habitaciones, lo que puede convertirse tanto en un plus como en una espada de Damocles, dada nuestra particular y conservadora forma de vida. Si será finalmente la arquitectura la que maneje los hilos o nuestro anquilosado sistema de vida lo que predomine, marcarán el éxito o el fracaso de la apuesta arquitectónica de Chauriye y Stäger.

Un elemento común a toda la obra es el alejamiento casi compulsivo que hacen los arquitectos de las soluciones tipo que recorren gran parte de nuestra ciudad. En este espectro, la solución del ingreso en un costado separado por una batería de pilares circulares de la plaza dura que aumenta el tamaño de la vereda; el modelo estructural que implica limpieza espacial y recibe todo el volumen del edificio con un pilar en forma de V; la forma de trabajar las barandas en vidrio para permitir una mayor transparencia; la disposición del volumen del edificio como un objeto singular en el centro del predio; el colo blanco de las fachadas que resalta aún más su condición de pieza única desconectándose del entorno inmediato o la geometría y el ritmo de las ventanas dispuestas ya sea horizontal o verticalmente marcan una cierta obsesión por salirse de la media e innovar en un medio que en muchos casos ha carecido de aquello durante demasiados años.

Sin perjuicio de lo anterior, esta manera de actuar frente al mundo inmobiliario conlleva, inevitablemente, un riesgo implícito, toda vez que, más allá de los aplausos o los palmoteos de nuestro medio por el resultado arquitectónico, lo que realmente está en juego aquí es que la ecuación entre arquitectura y negocio inmobiliario funcione a cabalidad. El problema es que tanta especificidad en la solución sumado a la preponderancia de la arquitectura de autor por sobre otras consideraciones consustanciales a este tipo de operaciones, supone un riesgo alto a la hora de encontrar aceptación en un mercado que si bien no tiene exigencias desproporcionadas, sí cuenta con ciertas premisas básicas que difícilmente entrará a transar. Tema aparte en este aspecto, es la solución que define las barandas de los balcones a través de una sola pieza de vidrio lo que genera una sensación de inseguridad tan grande como la de transparencia.

En definitiva, la decisión de optar por la arquitectura, en estos casos, implica asumir dichos riesgos, lo que siempre, mirado desde la óptica del arquitecto, será saludado y aplaudido. Por el momento, nos quedaremos con ese aspecto como el mayor aporte del edificio, porque al final del día lo importante es que la arquitectura por sí misma tenga la capacidad de seducir a un medio que en su generalidad premia valor por sobre calidad. Si en este caso la calidad se impone, habremos dado un paso importante en la finalidad de ofrecer desde la vereda de la arquitectura una opción que a través de su desarrollo prometa mejorar la vida con sólo habitar los espacios que ésta ofrece generosamente. 


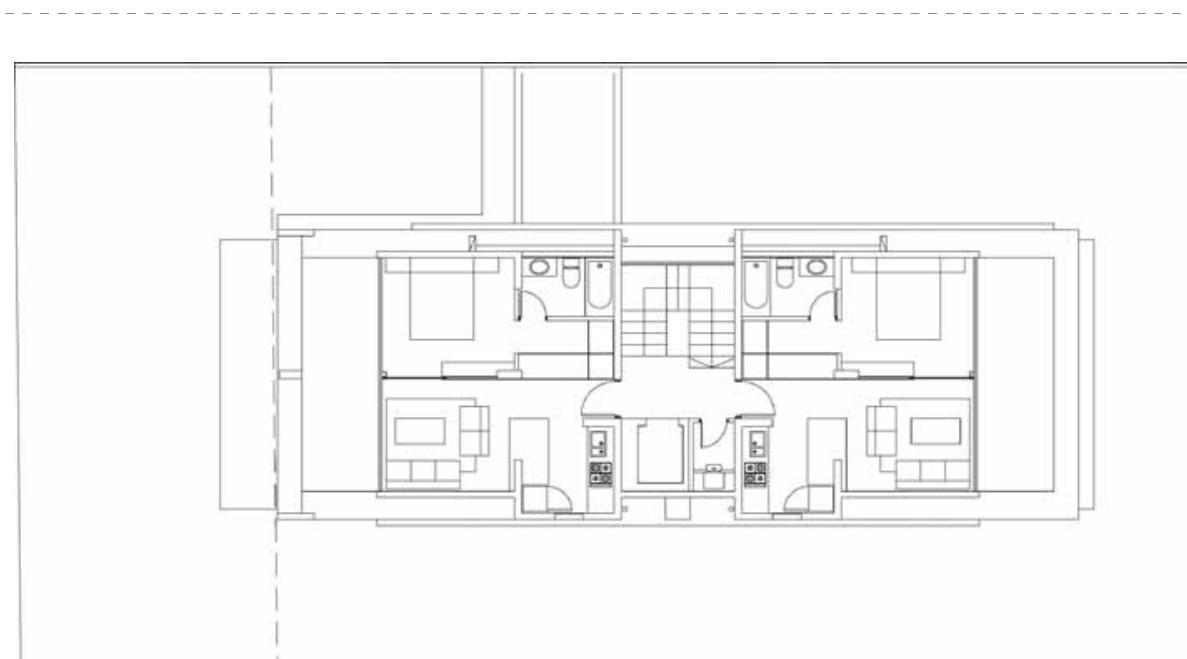

Comeanem

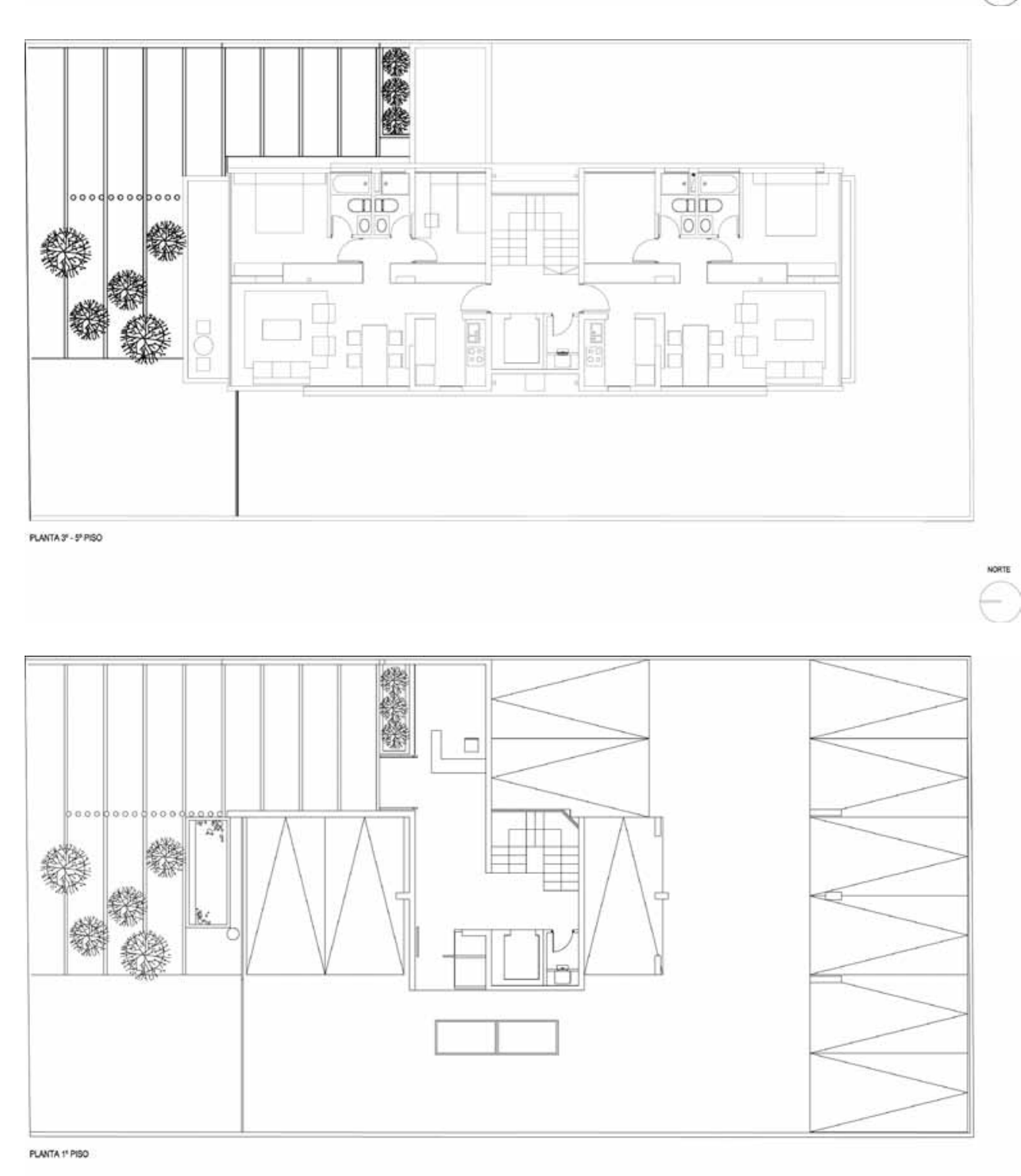

$\bar{\epsilon}$ 

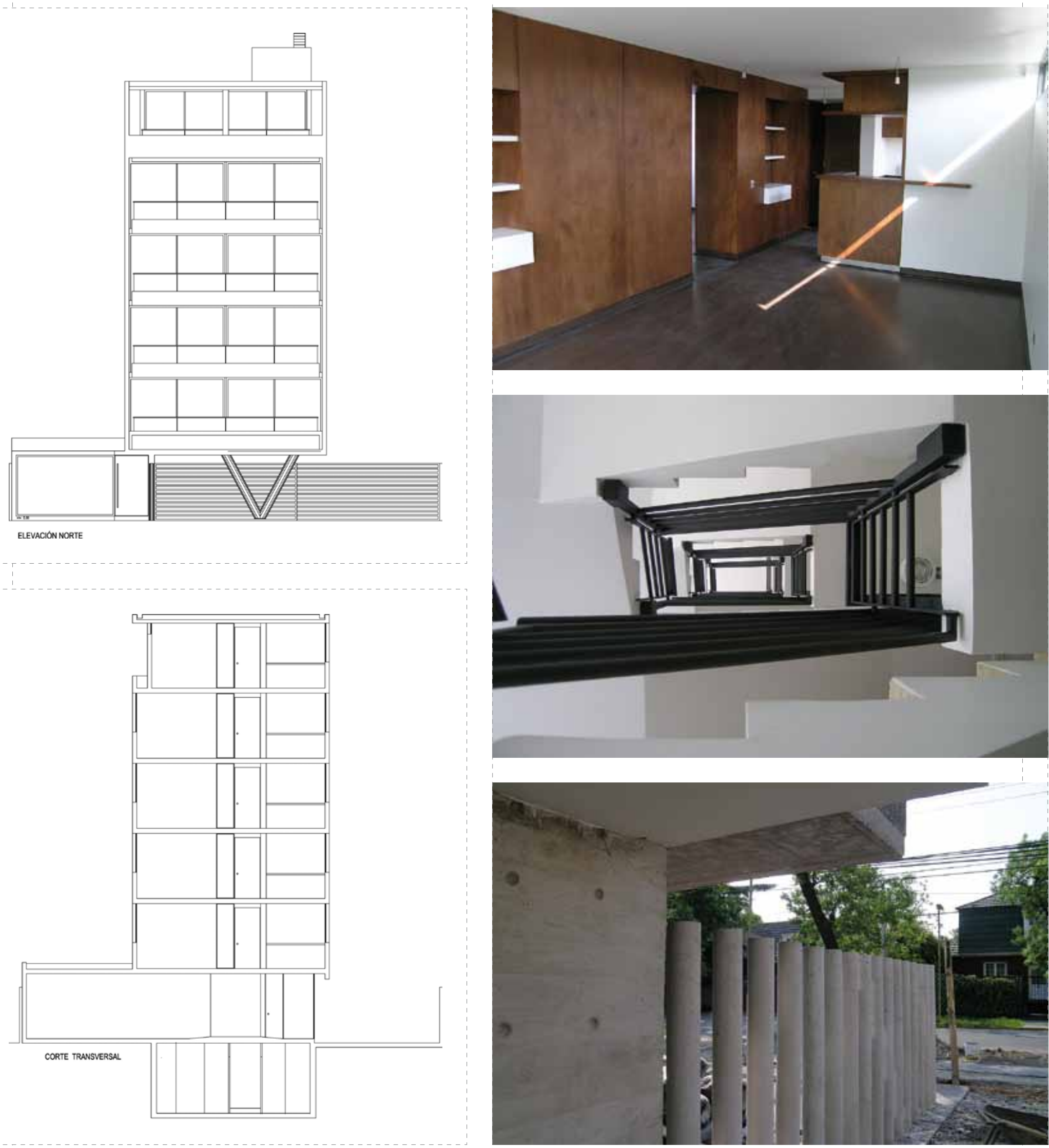

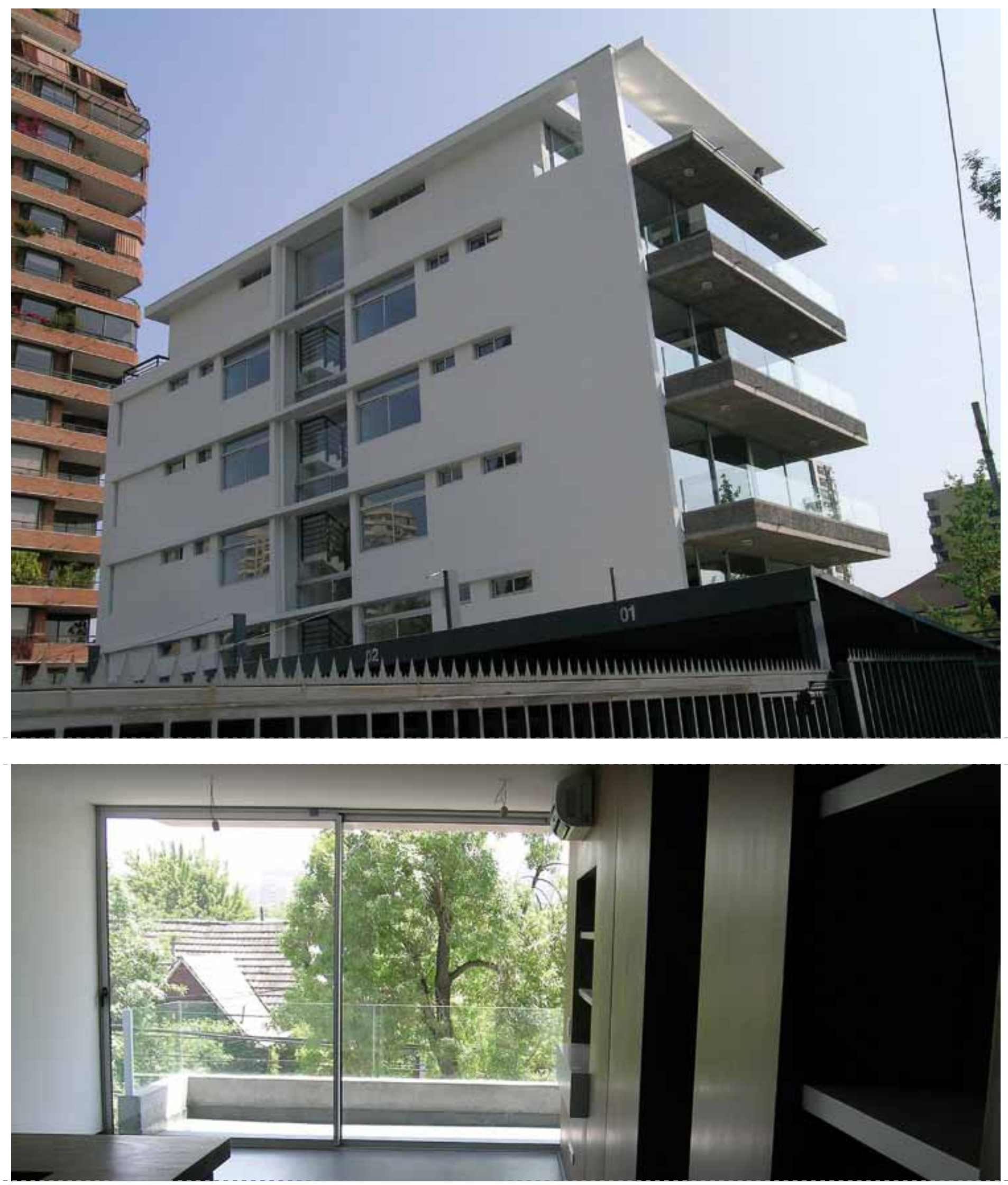


\section{N 016}

de arquitectura
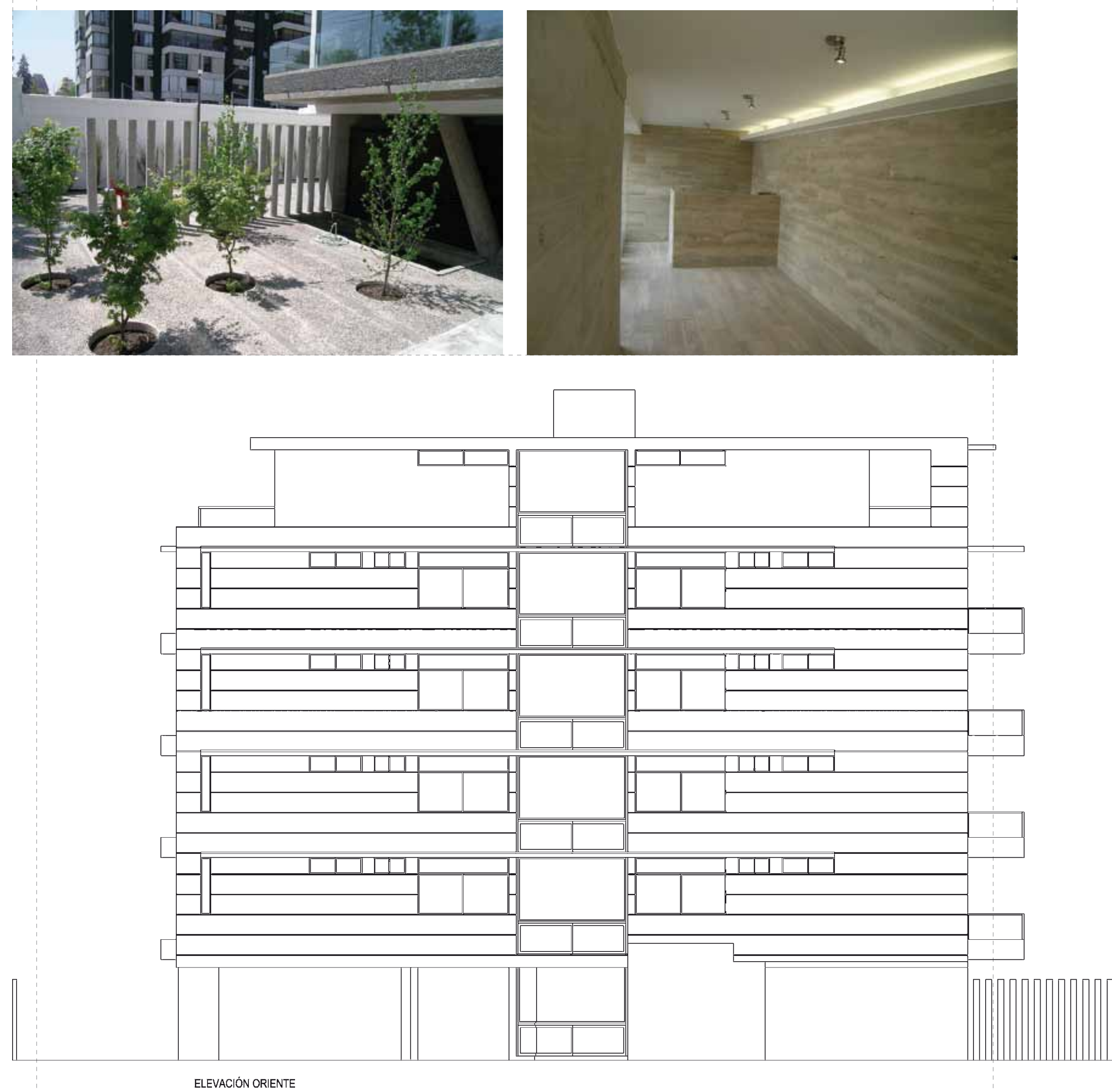
Ficha técnica

- Titulo de la obra Edificio Atenea

- Arquitectos

Chauriye Stäger Arquitectos

Rodrigo Chauriye

Beatriz Stäger

- Constructor

Roberto Chauriye

(Constructora Santa Laura)

- Calculista

Jorge Flores

- Otros profesionales

Osvaldo Moreno (Arquitecto Asociado)

Pablo Inostroza (Arquitecto Colaborador)

- Ubicación

Av. Martín de Zamora 3385, Las Condes, Santiago, Chile

- Superficie

$752 \mathrm{~m}^{2}$

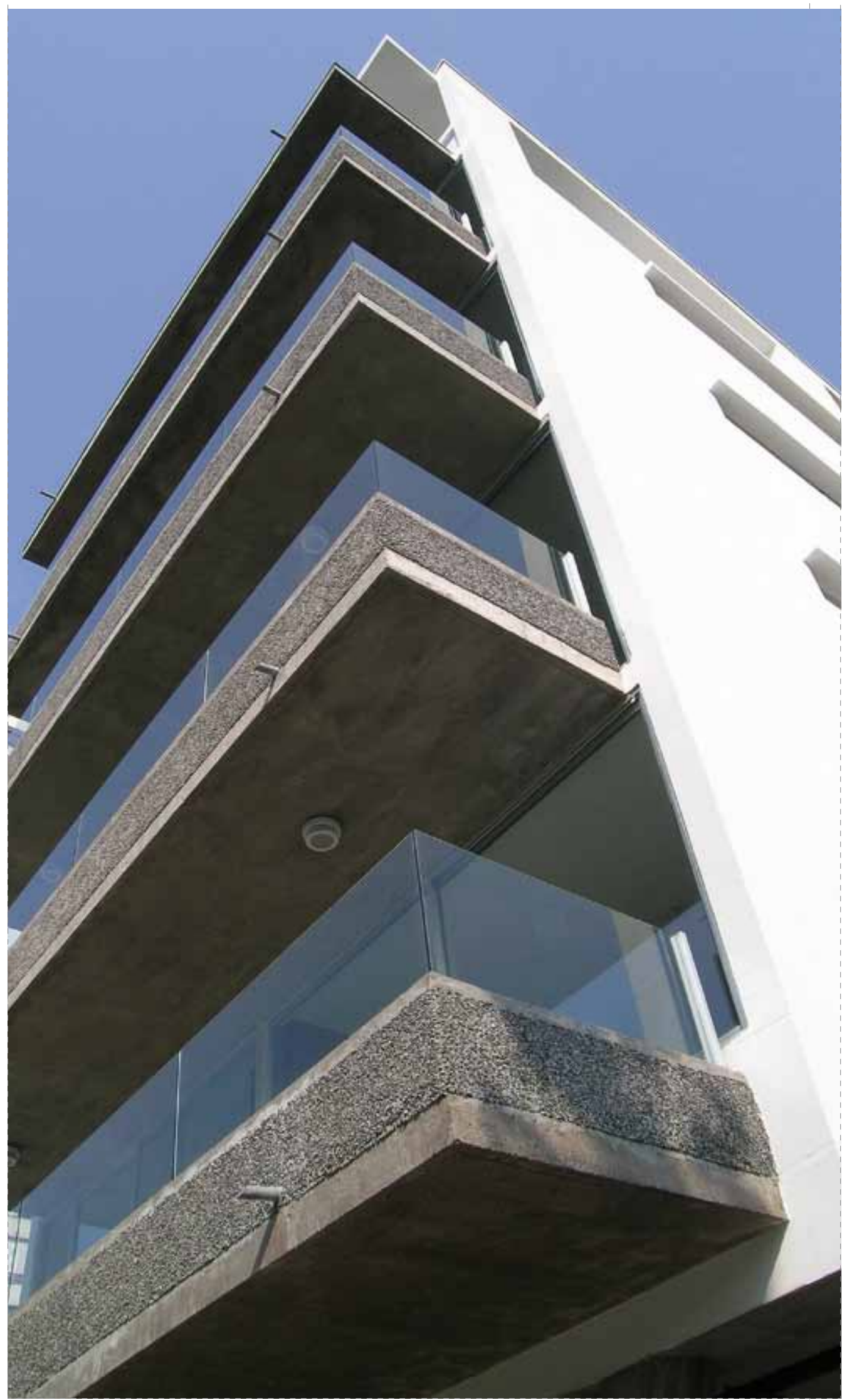

